mental ideas at the basis of modern mathematical analysis. No attempt is made to go deeply into any particular aspect of the various subjects. Prof. Smail's book will be welcomed by University students reading for an honours course in mathematics, the only other systematic English treatise, Dr. Bromwich's "Infinite Series," being now out of print. It is unfortunate that the book has been issued at so high a price.

W. E. H. B.

Quantitative Chemical Analysis: Adapted for Use in the Laboratories of Colleges, of Technical Institutes, and of Analysts. By Dr. F. Clowes and J. B. Coleman. Twelfth edition. Pp. xxiv +576 . (London: J. and A. Churchill, r924.) I8s. net.

"Clowes and Coleman" is so well known that it is only necessary to state that the new edition will be found as useful as those of the past. There are a few points which might be suggested in the way of improvement. The method of weighing by vibrations is so superior to the zero method that it is now generally used, but the statement that " consecutive swings to the right and to the left must finally be equal in extent " (p. 9) is not satisfactory. The correct method should be explained. The methods used in the calibration of volumetric apparatus are also approximate only, but are suitable for elementary students. The analysis of industrial products is a special and valuable feature, but some of the newer methods (e.g. the reduction of nitrates by Devarda's alloy) are not given. The range of exercises is extensive, and the book may be recommended to students and analysts as an excellent introductory treatise and work of reference.

The Boys' Own Book of Science. By F. L. Darrow. Pp. $\mathrm{x}+33^{\mathrm{r}}$. (New York: The Macmillan Co.; London: Macmillan and Co., Ltd., I923.) Ios. $6 d$. net.

Ar a time when popular books on science over-emphasise the hypothetical and speculative, it is pleasing to find one in which chemistry is treated as an experimental science. The experiments are chosen for performance in the private laboratory, yet they are all instructive, deal with real problems, and in some cases, e.g. those with the electric furnace, call for considerable skill. The details are carefully given, and the reviewer, with memories of early failures, finds the pitfalls clearly marked. The dangerous character of a mixture of potassium permanganate and sulphuric acid should, however, have been mentioned on p. $2 x$. The brief historical notices of famous chemists are sure to prove inspiring, and the book as a whole is written in an easy yet dignified style, which is most attractive. It should be a popular gift. The illustrations are excellent, and the only slip noticed was in the description of the experiment on the density of air on p. 6o. In all cases the scientific value of the work is clearly in evidence.

L'Audition et ses variations. Par Dr. Marage. Pp. 262. (Paris: Chez l'auteur, I9 rue Cambon, I923.) n.p.

THE work under notice is written mainly from the point of view of the physiologist or medical specialist. It covers a very wide field, and in consequence some portions receive only a slight treatment. The subjectmatter of the book falls into twelve chapters, their topics being as follows: auditive acuteness; normal ears; auditive re-education, acoustical and clinical: deafness of various kinds; deaf mutes; auditive acuteness after cerebro-spinal meningitis; deafness through the War (this chapter is specially full with some guidance as to treatment recommended); buzzings in the ear; hearing horns; protection from loud sounds; telephonic audition; location of submarines and the threshold of audition. The thirteenth chapter is a bibliography of the author's works (more than eighty in number) from 1887 to 1923 . The work has a number of tables, illustrations of apparatus, and graphs of vibrations.

E. H. B.

Diagnostic Methods: a Guide for History taking, Making of routine Physical Examinations and the usual Laboratory Tests necessary for Students in Clinical Pathology, Hospital Internes, and Practicing Physicians. By Prof. Herbert Thomas Brooks. Fourth edition. Pp. rog. (London: Henry Kimpton, 1923.) 8s. 6 d. net.

THIs little book is limited mainly to laboratory methods, the descriptions of which are brief but clear. For the simpler pathological investigations most of the recommendations given are good; the Tallquist hæmoglobinometer, which is suggested "for rapid bedside work," is so inaccurate as to be quite useless. The more complicated tests, such as the Wassermann, Lange's colloidal gold, and the complement fixation for gonorrhœea, are best left entirely to the pathologist, since their use in unskilled hands is likely to be misleading to a dangerous degree. The book is too brief to be of value to students and too simple for the pathologist, but the practitioner will find in it real assistance in carrying out and interpreting the simpler pathological tests.

\section{Éléménts de la théorie électromagnétique de la lumière.}

Par Prof. Ludwik Silberstein. Traduit de l'anglais par Georges Matisse. Pp.vi + 95. (Paris: GauthierVillars et Cie, r923.) 6 francs.

THIS is a translation of the excellent booklet on the electromagnetic theory of light published by Dr. Silberstein in English a few years back and then noticed in NATURE (November 2I, I9I8, p. 225). It is derived ultimately from the author's Polish treatise on electricity and magnetism. The translator has added notes in explanation of some of the mathematical arguments and of the vectorial notation adopted by the author. Some appendices are omitted, but a special note has been added by the author on Poynting's vector.

$$
\text { S. B. }
$$

Populär-roissenschaftliche Vorlesungen. Von Prof. Dr. E. Mach. Fünfte vermehrte und durchgesehene Auflage. Pp. xï $+628+7$ Tafeln. (Leipzig: J. A. Barth, r923.) Grundzahl : Io marks.

THIs well-known classic appears, practically unaltered, in a fifth edition. We can only hope that the appearance of new editions indicates that the book is still alive, and is as popular and influential with the new generation as it was with the old. 